Introduction A particular sub-population known to be at high risk of tuberculosis (TB) infection is health workers, with rates of infection estimated at 2-5 times that of the general population. Evidence indicates that Infection control practices are poorly implemented. The objective of this study was to investigate perceptions of knowledgeable informants regarding the macro level drivers of $\mathrm{TB}$ infection in the healthcare setting and explore their perceptions of barriers as well as actions that could enhance the capacities to prevent and control TB infection among HCW.

Methods This qualitative study involved semi structured interviews with 18 stakeholders working in occupational health and TB management in South Africa. These included 10 government authorities with responsibility for TB control, 4 academic experts, 2 TB advocacy group members, a legislator, and a hospital CEO. Interviews were audio recorded and transcribed verbatim, validated and analysed aided by Nvivo 11 qualitative data management software.

Results Perceptions of the major drivers of occupationallyacquired TB that emerged from the key informant interviews included: the high incidence in the general population, budgetary constraints in healthcare system allocation, inadequate human resources dedicated to occupational health $(\mathrm{OH})$, poor implementation culture, the nature of governance of $\mathrm{OH}$ related issues, lack of priority for $\mathrm{OH}$, and other socio-cultural factors. Improvement in the governance of TB related issues, priority setting and implementation and adherence to occupational health and safety policies were identified as crucial to improving TB prevention and control strategies

Discussion Occupational health and safety is seen as lacking in priority in the healthcare system. Although a national TB policy for HCWs will soon be launched, it is perceived that implementation and adherence to such policies remain problematic due to a chronic underfunding of the health sector in general.

\section{ACTIVITY OF DOKTOR24 COMPANY GROUP, CLOSE COOPERATION OF OCCUPATIONAL HEALTH,OSH, PREVENTION. PRESENTATION OF GOOD PRACTICE FROM LARGE PROVIDER IN HUNGARY}

Éva Ruzsás, Barnabas Biró, Antal Sándor Nikl. Doktor24 - Medicina B.M. Ltd, Budapest, Hungary

\subsection{6/oemed-2018-ICOHabstracts.524}

Presentation of the legal environment in Hungary:

- Cancun Charter, ICOH National Secretariat and the role of ICOH Hungarian National Secretariat in the survival of occupational health in Hungary

- statistics

- Introduction of Doktor24 company group - Professionally diverse tasks, closed and open clinics, maior central clinic

- Close relationship between occupational health and work safety - Mandatory flow of information on labour accidents

- First aid training - vocation

- Rapid growth of the role of labour psychologist

- Prevention programs - Their public health significance due to mandatory occupational health examinations

- Weight control program
- Bodywakes Lifestyle Consultant Program

- Smoking cessation intervention programme

- Cardiovascular screening

- Melanoma screening

- Promotion of the need for regular exercise - Fitness room operation

\section{PREVENTION OF COMMON MENTAL DISORDERS IN EMPLOYEES - ATTITUDES OF HEALTH CARE PROFESSIONALS, HUMAN RESOURCES MANAGERS, AND EMPLOYEES IN GERMANY}

${ }^{1} \mathrm{MA}$ Rieger*, 'S Burgess, ${ }^{2} \mathrm{~F}$ Junne, ${ }^{3} \mathrm{E}$ Rothermund, ${ }^{3} \mathrm{H}$ Gündel, ${ }^{2} \mathrm{~S}$ Zipfel, ${ }^{1,4} \mathrm{M}$ Michaelis. ${ }^{1}$ Institute of Occupational and Social Medicine and Health Services Research, Tübingen, Germany; ${ }^{2}$ Department of Psychosomatic Medicine and Psychotherapy, University Hospital Tübingen, Germany; ${ }^{3}$ Department of Psychosomatic Medicine and Psychotherapy, University Hospital Ulm, Germany; ${ }^{4}$ Freiburg Research Centre for Occupational and Social Medicine, Freiburg, Germany

\subsection{6/oemed-2018-ICOHabstracts.525}

Introduction Many studies investigate the possible positive and negative effects of work-related factors on mental health of employees, but only little is known about the attitudes of the persons involved. Therefore we aimed to assess the perceptions of occupational health physicians (OHP), primary care physicians (PCP), psychotherapists (PT), human resources managers (HRM), and employees (EMP) with regard to workrelated risk factors and possibilities for prevention of common mental disorders (CMD) at the workplace.

Methods A standardised questionnaire was developed to assess the individuals' attitudes with regard to different aspects of prevention of CMD in employees. The survey assessing the estimates concerning work-related and individual risk factors, cooperation of persons involved, and engagement of specific institutions first was developed for a postal survey among OHPs, PCPs, PTs, and HRMs in 2014. ${ }^{1}$ Second, the content was slightly adapted to perform an online survey among employees addressing an online access panel in 2016. Besides descriptive measures or explorative bivariate methods, multivariate logistic regression analysis with IBM SPSS 22 was computed.

Results Data were gathered from 133 OHPs (response rate 30\%), 136 PCPs (14\%), 186 PTs (27\%), 172 HRMs (12\%) and 610 EMPs (stipulated number of participants). The significance of several work-related factors (e.g. work-related demands, work organisation) for the development of CMD in employees was judged rather similarly by the health professionals but lower by HRM. The employees' perception often led between both. Individual predisposition for CMD was rated less important by HRM and EMP than by health professionals. The potential of work-related aspects for prevention of CMD was assess similarly high by health professionals and EMP, but slightly lower by HRM.

Discussion The multiperspective survey revealed different answering patterns of the five groups indicating possibilities as well as need for further actions with regard to work-related prevention of CMD in employees.

\section{REFERENCE}

1. Michaelis, et al. Mental Health \& Prevention 2016;4:88-95. 


\section{History of Prevention of Occupational Diseases}

\section{ICOH CONGRESSES PROCEEDINGS REPOSITORY: HEALTH HERITAGE IN OPEN ACCESS}

C Petyx*, V Boccuni, P Dionisi, P Fruscella, M Petyx, BM Rondinone, F Boccuni, A Valenti, $S$ lavicoli. INAIL, Department of Occupational and Environmental Medicine, Epidemiology and Hygiene, Rome, Italy

\subsection{6/oemed-2018-ICOHabstracts.526}

Introduction Inail has for a long time been active in the recovery, valorization and sharing of the heritage of knowledge relating to health and safety at work, both at a national and international level. Among the activities of the triennial research plan, it is also included the creation of a repository of the ICOH Congress proceedings, starting from its foundation to the present time, with the aim of presenting the available documentation in an organised and interrelated system.

Methods The series of ICOH international congresses begins in Milan in 1906, in connexion with the foundation of ICOH. To date, 31 international congress have been held. On the occasion of the centenary Congress in 2006, a first catalogue and digitalization of the proceedings was created, with an index by author, title keywords, etc., by the Clinica del Lavoro of Milan, under the direction of P.A. Bertazzi. The aim of the project is to complete the digital version of the single proceedings for the realisation of a web edition of the complete corpus of the ICOH Congresses, along with the development of organised metadata useful for semantic research.

Result The result will be the realisation of a critical review in order to level out all the previous experiences of digitalization of the proceedings of the $\mathrm{ICOH}$ Congresses, including the various forms of indexing now existing, along with the creation of a thesaurus of keywords for occupational medicine, in digital format and with links to the entries.

Research output will include the creation of a structured Repository containing a series of shared metadata in open access and with tools for semantic research.

Discussion The Repository will be released at the ICOH 2018 Congress and will constitute an important research tool not only for the history of prevention and health and safety at workplaces, but also for the current research activities in OHS.

\section{OCCUPATIONAL MENTAL DISORDER IN JAPAN, KOREA, AND TAIWAN: AN UPDATE OF INFORMATION}

${ }^{1}$ Heng-Hao Chang*, ${ }^{2}$ Sung-Shil Lim. 'Department of Occupational and Environmental Medicine, National Cheng Kung University Hospital, Tainan, Taiwan; ${ }^{2}$ Institute for Occupational Health, Yonsei University College of Medicine, Seoul, Korea

\subsection{6/oemed-2018-ICOHabstracts.527}

Introduction Mental disorder due to work stress has been a serious problem worldwide, particularly in East Asian countries including Japan, Korea and Taiwan, where long working hour was prevalent. This study aimed to compare the trend and characteristics of occupational mental disorder and suicide, as well as the national policy for preventive measures in these three countries.
Methods A comprehensive literature search of relevant articles in English were retrieved from PubMed, irrespective of publication date. The search keywords used were occupational, work-related, mental, psychiatric, compensation, compensated, Korea, Japan, and Taiwan. Official statistical data, recognition guideline and national preventive measures regarding occupational mental disorder in respective countries were also obtained.

Results In Japan, the number of compensated cases of occupational mental disorder has increased substantially since 1999, particularly among young workers. While in Korea, the trend was more steadily increasing. However, in Taiwan only very small number of patients with mental disorder received compensation. An acute stressful event was the most common reason for approval in Korea. In Japan, change in workload and work quality accounted for an important stressor, including for the suicide cases.

Discussion The guideline for occupational mental disorder recognition came into place in Japan in 1999, and has influenced the development of guidelines in Korea in 2006 and Taiwan in 2009. All three countries recognised mental disorders as compensable occupational diseases, but the diagnosis entitled in the compensation insurance differed. Suicide due to workrelated issues was discussed particularly in the Japanese and Korean context. The criteria of Japan and Taiwan included evaluation of the strength of various types of work-related and non work-related stressors. National initiative of prevention of overwork-related mental disorder was established under Occupational Safety and Health Act in all three countries. A special act against Karoshi, including work-related suicide was also enacted in Japan.

\section{ARCHIVING HISTORICAL DOCUMENTS: MAINTAINING OUR HISTORY}

Gino G Fazio*. National Institute for Occupational Safety and Health, Cincinnati, Ohio, USA

\subsection{6/oemed-2018-ICOHabstracts.528}

Aim of special session This workshop will cover the importance of archiving essential historical documents in occupational health

Gino Fazio, Garrett Burnett

National Institute for Occupational Safety and Health, Cincinnati, Ohio, USA

\section{5a ARCHIVING KEY HISTORICAL DOCUMENTS: CHOICES AND PLATFORMS}

GG Fazio, JG Burnett. National Institute for Occupational Safety and Health, Cincinnati, Ohio, USA

\subsection{6/oemed-2018-ICOHabstracts.529}

Introduction The History of Prevention of Occupational and Environmental Diseases project highlights an important challenge facing the occupational safety and health community. As the web archive states, 'The history of occupational and environmental medicine is rich, but has largely been relegated to passing notice or ignored altogether, even by specialists in the field.' On the rare occasion occupational and environmental disease history is mentioned, it is most often limited to biographical sketches and references-not complete profiles of individuals who have made significant contributions nor the 